\title{
Neutrophil chemokines in bronchoalveolar lavage fluid and leukocyte-conditioned medium from nonsmokers and smokers
}

\author{
D. Morrison*, R.M. Strieter+, S.C. Donnelly*, M.D. Burdick+, S.L. Kunkel++, W. MacNee*
}

Neutrophil chemokines in bronchoalveolar lavage fluid and leukocyte-conditioned medium from nonsmokers and smokers. D. Morrison, R.M. Strieter, S.C. Donnelly, M.D. Burdick, S.L. Kunkel, W. MacNee. OERS Journals Ltd 1998.

ABSTRACT: Polymorphonuclear neutrophils (PMN) have been implicated in the pathogenesis of emphysema. The chemokines interleukin-8 (IL-8), growth-related oncogene $($ GRO- $\alpha)$ and extractable nuclear antigen (ENA)-78 may be involved in the increased numbers of PMN in smokers' airspaces.

The levels of these cytokines in bronchoalveolar lavage fluid (BALF) and bronchoalveolar lavage leukocyte conditioned medium (LCM), along with BALF PMN numbers in 12 smokers who abstained for $12 \mathrm{~h}$ (chronic smoking) or continued to smoke until $1 \mathrm{~h}$ before study (acute smoking) and seven nonsmokers were compared.

Neutrophils in BALF increased in acute $\left(1.96 \pm 0.53 \%, 0.99 \pm 0.32 \times 10^{6}\right.$ cells $)$ compared with chronic smokers $\left(0.59 \pm 0.25 \%, 0.61 \pm 0.24 \times 10^{6}\right.$ cells, $\mathrm{p}<0.05$ nonsmokers $)$ and nonsmokers $\left(0.79 \pm 0.29 \%, 0.05 \pm 0.01 \times 10^{6}\right.$ cells, $\left.p<0.05\right)$. There were no differences in IL-8 or GRO- $\alpha$ in BALF between smokers and nonsmokers. ENA-78 levels were lower in smokers $(p=0.006)$. There was no difference in IL-8, GRO- $\alpha$ or ENA-78 in LCM from unstimulated cells in smokers versus nonsmokers. After stimulation with lipopolysaccharide (LPS) $10 \mathrm{ng} \cdot \mathrm{mL}^{-1}$, IL-8 release in acute smokers $(\mathrm{p}=0.04)$ and GRO- $\alpha$ release in smokers $(p=0.009)$ were significantly higher than in nonsmokers. Following stimulation with LPS $100 \mathrm{ng} \cdot \mathrm{mL}^{-1}$, GRO- $\alpha$ release was higher in smokers $(p=0.03)$ and increased further in acute smokers $(p=0.02$ versus nonsmokers, $p=0.04$ versus chronic smokers) and ENA-78 release increased in smokers ( $\mathrm{p}=0.02$ versus nonsmokers).

In conclusion, influx of polymorphonuclear neutrophils into smokers' airspaces is an acute phenomenon and neutrophil chemokine release from mixed bronchoalveolar lavage leukocytes is influenced by cigarette smoking and endotoxins.

Eur Respir J 1998; 12: 1067-1072.
*Respiratory Medicine Unit, Dept of Medicine, University of Edinburgh, Edinburgh, UK. Depts of +Pulmonary and Critical Care and +Pathology, University of Michigan, Ann Arbor, MI, USA

Correspondence: W. MacNee

Respiratory Medicine Unit

Dept of Medicine

Royal Infirmary

Edinburgh EH3 9YW

UK

Fax: 441315363255

Keywords; Bronchoalveolar lavage fluid chemotactic factors

lipopolysaccharides

polymorphonuclear leukocytes smoking

Received: July 241997

Accepted after revision July 31998

Supported by the Chest, Heart and Stroke Association (Scotland) and the British Lung Foundation.
Neutrophils have been implicated in the pathogenesis of the centrilobular form of emphysema that is associated with cigarette smoking, by the release of both oxidants and proteases. It is hypothesized that destruction of the alveolar structure in emphysema is mediated by increased proteolytic activity, owing to an imbalance between proteases, especially elastase, and $\alpha_{1}$-protease inhibitor $\left(\alpha_{1}-\mathrm{Pi}\right)$. The neutrophil is the main cellular source of elastase in the lung. Oxidants both in cigarette smoke and released from neutrophils can inactivate $\alpha_{1}-\mathrm{Pi}$. Normal distal airways contain a small number of neutrophils. The total number of inflammatory cells and the number of neutrophils in the airspaces of smokers are increased [1]. This may be mediated through the release of chemotactic factors such as complement factor 5a (C5a), leukotriene $\mathrm{B}_{4}\left(\mathrm{LTB}_{4}\right)$ and interleukin (IL)-8. Cigarette smoking delays and possibly activates neutrophils within the pulmonary vascular bed [2], which acts as a large reservoir for cells. The recruitment and activation of neutrophils involves the upregulation of local ad-hesion molecules and chemotaxis from the vasculature into the airway mucosa and alveoli along established chemotactic gradients [3].
Specific cytokines (CXC chemokines) including IL-8 are chemotactic for specific cell populations. The supergene family of chemokines includes a number of peptide analogues that have in common four conserved cysteine residues in identical locations, with the first pair of cysteines separated by one amino acid [4]. IL- 8 is a potent neutrophil chemoattractant and activator that is released by alveolar macrophages and airway epithelial cells. It was originally isolated from peripheral blood monocytes. Other cellular sources include endothelial cells, fibroblasts and neutrophils themselves. IL- 8 production by these cells is stimulus specific [3]. It is elevated in bronchoalveolar lavage fluid (BALF) from patients with interstitial lung disease [5] and in patients at risk and who subsequently progress to the adult respiratory distress syndrome (ARDS) [6], both of which are associated with an accumulation of neutrophils in the lungs. IL-8 maintains its biological activity in the presence of significant changes in $\mathrm{pH}$ and resists mild proteolytic degradation compared with other known chemotactic factors. As a result, it may have prolonged in vivo activity for the recruitment of neutrophils at sites of acute inflammation [3]. Growth-related oncogene 
(GRO- $\alpha$ ) was originally described as a mitogen for human melanoma cells [4]. It is also produced by monocytes [7], endothelial cells [8], epithelial cells and alveolar macrophages [9], and by fibroblasts and synovial cells [10]. It is also a chemoattractant for human neutrophils [3, 4]. Extractable nuclear antigen (ENA)-78 is a 78 amino acid peptide which is unique in that it was originally isolated and cloned from an IL-1-stimulated human pulmonary epithelial cell line A549 [3]. Like IL-8, it was identified on the basis of its ability to induce neutrophil activation and chemotaxis [4]. It is also produced by human primary culture renal tubule epithelial cells in response to IL-1 $\beta$ [11].

This study compares the concentrations of the CXC chemokines IL-8, GRO- $\alpha$ and ENA-78 in both BALF and leukocyte-conditioned medium (LCM) with airspace neutrophil numbers in nonsmokers and healthy cigarette smokers. The chronic and acute effects of cigarette smoking on the above were studied. In addition, chemokine release from mixed bronchoalveolar lavage (BAL) leukocytes was compared with or without stimulation by lipopolysaccharide (LPS) in order to assess the effect of a second stimulus such as may occur in sepsis.

\section{Methods}

\section{Subjects}

Twelve regular cigarette smokers underwent bronchoscopy and BAL after either abstaining from cigarette smoking for $12 \mathrm{~h}$ (chronic smoking) or $1 \mathrm{~h}$ after smoking two cigarettes (G2, Imperial Tobacco, WD \& HD Wills, Bristol, UK) to a standard protocol [2] (acute smoking). Three subjects were studied twice; thus eight chronic studies and seven acute studies were performed. Seven control subjects who had never smoked were also studied. None of the subjects had a history of respiratory infection within 6 weeks of the study. The characteristics of the subjects are given in table 1 . The nonsmokers were significantly younger than the acute group $(\mathrm{p}<0.05)$, in whom forced expiratory

Table 1. - Subject characteristics

\begin{tabular}{|c|c|c|c|c|}
\hline & $\begin{array}{l}\text { Chronic } \\
\text { smoking }\end{array}$ & $\begin{array}{c}\text { Acute } \\
\text { smoking }\end{array}$ & $\begin{array}{c}\text { Non- } \\
\text { smokers }\end{array}$ & P-value \\
\hline Subjects $n$ & 8 & 7 & 7 & \\
\hline Sex M:F & $6: 2$ & $5: 2$ & $5: 2$ & \\
\hline Age yrs & $40 \pm 4$ & $44 \pm 4$ & $32 \pm 1$ & $<0.05 \mathrm{~A} v s \mathrm{NS}$ \\
\hline Range & $26-52$ & $26-56$ & $26-36$ & \\
\hline FEV1 L & $3.7 \pm 0.2$ & $3.3 \pm 0.4$ & $4.4 \pm 0.3$ & $<0.05$ A $v s$ NS \\
\hline$\%$ pred & $94 \pm 5$ & $90 \pm 8$ & $107 \pm 6$ & NS \\
\hline $\begin{array}{l}\text { Cigarettes } \\
\text { daily } n\end{array}$ & $20.6 \pm 2.2$ & $23.6 \pm 3.4$ & $\mathrm{n} / \mathrm{a}$ & NS \\
\hline Range & $15-30$ & $15-40$ & & \\
\hline $\begin{array}{l}\text { Pack-yrs } \\
\text { range }\end{array}$ & $\begin{array}{l}24 \pm 4 \\
7-33\end{array}$ & $\begin{array}{l}33 \pm 7 \\
7-65\end{array}$ & $\mathrm{n} / \mathrm{a}$ & NS \\
\hline $\mathrm{COHb} \%$ pre & $3.0 \pm 0.2$ & $4.8 \pm 0.5$ & $1.2 \pm 0.1$ & $\begin{array}{l}<0.001 \mathrm{C} v s \mathrm{~A} \\
<0.01 \mathrm{C} v s \mathrm{NS} \\
<0.001 \mathrm{~A} v s \mathrm{NS}\end{array}$ \\
\hline post & & $7.1 \pm 0.5$ & & $<0.001$ vs pre \\
\hline
\end{tabular}

Values are mean \pm sEM. M: male; F: female; FEV1: forced expiratory volume in one second; $\mathrm{COHb}$ : carboxyhaemoglobin; n/a: not applicable; A: acute smoking; NS: nonsmokers; C: chronic smoking; ns: nonsignificant. volume in one second (FEV1) $(\mathrm{L})(\mathrm{p}<0.05)$, but not FEV1 $\%$ predicted was significantly lower. Carboxyhaemoglobin $(\mathrm{COHb})$ in the nonsmokers was significantly lower than in either the acute $(\mathrm{p}<0.001)$ or chronic $(\mathrm{p}<0.01)$ smoking group. It was significantly higher before acute smoking than in the chronic group $(\mathrm{p}<0.001)$ and was further increased after smoking two cigarettes $(\mathrm{p}<0.001)$. There was no change in spirometry following acute cigarette smoking.

Ethical permission was obtained from the local medical ethics committee and all of the subjects gave informed written consent.

\section{Bronchoscopy and bronchoalveolar lavage}

Subjects were sedated with cyclimorph (5-10 mg i.v.) immediately before the procedure and atropine ( $0.6 \mathrm{mg}$ i.v.) was given. Topical lignocaine was applied to the nasopharynx $(4 \% 0.5 \mathrm{~mL}$ and $2 \% 2 \mathrm{~mL})$ and to the vocal cords and major airways $(2 \% 6 \mathrm{~mL})$. Spiggots, Y-connectors, bottles and caps were obtained from A. and J. Beveridge (Edinburgh, UK) and reused after sterilization. The catheters (14 suction catheters, $50 \mathrm{~cm}$ ) were supplied by Mediplast (Taby, Sweden), A60 extension sets (1,250 mm wide bore) by Avon Medicals (Hythe, UK) and two-way taps (865.00) by Vygon (Cirencester, UK). The bronchoscope was wedged into a segment of the middle lobe or lingula. BAL was performed before any other manoeuvre. Warmed normal saline $(240 \mathrm{~mL})$ in $30 \mathrm{~mL}$ aliquots was introduced and aspirated immediately. Subjects were given oxygen $\left(2-3 \mathrm{~L} \cdot \mathrm{min}^{-1}\right)$ throughout the procedure.

The BALF was immediately filtered through a sterile funnel (A. and J. Beveridge) through four sterile gauze swabs and then centrifuged at $250 \times g$ for $10 \mathrm{~min}$ at $4^{\circ} \mathrm{C}$ to remove most of the cells. The supernatant was centrifuged again at $1,000 \times g$ for $10 \mathrm{~min}$ at $4^{\circ} \mathrm{C}$ to produce a completely cell-free fluid. The cell pellet was rinsed in Dulbecco's phosphate-buffered saline (PBS) (Gibco BRL, Paisley, UK) and counted using a haemocytometer. Viability was ascertained by Trypan blue exclusion. Cell differentials were performed on cytospin preparations (Shandon, Pittsburgh, PA, USA) stained with Diff Quik (Merz Dade, Geneva, Switzerland).

\section{Spirometry}

FEV1 and forced vital capacity (FVC) were both performed on a dry spirometer supplied by Vitalograph (Buckingham, UK). The best of three attempts was recorded and reproducibility maintained by ensuring that there was no more than $100 \mathrm{~mL}$ between the best two of each.

\section{Carboxyhaemoglobin}

Venous blood $(10 \mathrm{~mL})$ was taken into a lithium heparin tube for $\mathrm{COHb}$ measurement on an IL 282 co-oximeter (Instrumentation Laboratory, Lexington, MA, USA). Samples were stored at $4{ }^{\circ} \mathrm{C}$ and analysed in duplicate, the mean of the two measurements being taken. Care was taken to ensure that in samples stored before analysis only a minimal amount of air remained in the tube, to prevent deterioration. There was no change in measurements, on samples tested daily, and on up to 5 consecutive days. 
Results

Mixed BAL leukocytes were obtained from six chronic smokers and six acute smokers, with each being studied once. Only three nonsmokers provided sufficient cells (at least $9 \times 10^{6}$ in total). The cells were suspended at $1 \times 10^{6}$ $\mathrm{mL}^{-1}$ in Ham's F12 medium (Gibco) plus $0.2 \%$ low endotoxin bovine serum albumin (BSA) (Gibco), with $72 \mu \mathrm{g}$. $\mathrm{mL}^{-1}$ benzylpenicillin (Britannia Pharmaceuticals, Redhill, Surrey, UK), $50 \mu \mathrm{g} \cdot \mathrm{mL}^{-1}$ streptomycin (Evans Medical, Horsham, West Sussex, UK) and $40 \mu \mathrm{g} \cdot \mathrm{mL}^{-1}$ gentamicin (Roussel, Dublin, Ireland). They were incubated $\left(0.5 \times 10^{6}\right.$ cells $\cdot$ well $^{-1}$, six wells per intervention) for $18-20 \mathrm{~h}$ at $37^{\circ} \mathrm{C}$ (95\% air, 5\% $\mathrm{CO}_{2}$ ) in sterile 24-well tissue-culture plates (Greiner, Labortechnik, Dursley, UK) with or without LPS (10 or $100 \mathrm{ng} \cdot \mathrm{mL}^{-1}$; Sigma Chemical Co., Poole, UK). The cell supernatants were collected and centrifuged at $250 \times g$ for $10 \mathrm{~min}$ to ensure they were cell free and then stored at $-70^{\circ} \mathrm{C}$ and analysed in a single batch. The viability of the mixed leukocytes at this point was always $>95 \%$ by Trypan blue exclusion.

\section{Assays}

Concentrations of antigenic IL-8, GRO- $\alpha$ and ENA-78 were quantified using a modification of a double-ligand enzyme-linked immunosorbent assay, as described previously [12].

\section{Statistics}

Mean values for the subject and BAL characteristics of different groups were compared by one-way analysis of variance (ANOVA) with a Scheffé post hoc test, except where only two groups could be compared, in which case either an unpaired or a paired t-test was performed as appropriate. Mean values for IL-8, GRO- $\alpha$ and ENA-78 levels in the different groups were compared by the MannWhitney U-test. All calculations were performed on Statistica/Mac ${ }^{\mathrm{TM}}$, Release 1.7 (OStatSoft, 1991-1992, Cupertino, CA, USA). Data are expressed as mean \pm SEM. A p-value of $<0.05$ was considered statistically significant.

\section{Bronchoscopy and bronchoalveolar lavage}

The characteristics of the BAL are given in table 2 . The total number of cells recovered was 6.5 -fold greater in the acute smoking group than in the nonsmokers and 11.4fold greater in the chronic smoking group. There was no significant difference in either the volume of BALF recovered in the three groups or the viability of the cells recovered, which ranged $72-94 \%$.

There was a significant increase in the percentage and number of neutrophils in BALF obtained from the acute smoking group compared with the chronic smoking group $(p<0.05)$ and the nonsmokers $(p<0.05)$. Significantly increased numbers of macrophages $(\mathrm{p}<0.05)$ and lymphocytes $(\mathrm{p}<0.01)$ were obtained from the chronic smoking group compared with the nonsmokers.

\section{Chemokine measurements}

There were no differences in the levels of IL-8 and GRO$\alpha$ in BALF (table 3 ) from smokers compared with nonsmokers. ENA-78 levels were lower in the smokers than in the nonsmokers $(\mathrm{p}=0.006)$, There were no significant differences between the chronic and acute smoking groups. There was no difference in IL-8, GRO- $\alpha$ or ENA-78 concentrations in LCM from unstimulated mixed leukocytes from smokers compared with nonsmokers (table 4), or between the chronic and acute smoking groups. When stimulated with LPS at $10 \mathrm{ng} \cdot \mathrm{mL}^{-1}$, IL-8 release in the acute smoking group $(\mathrm{p}=0.04)$ and GRO- $\alpha$ release in smokers $(\mathrm{p}=0.009)$ was significantly higher than in nonsmokers (table 4). Following stimulation with LPS at $100 \mathrm{ng} \cdot \mathrm{mL}^{-1}$ GRO- $\alpha$ release was higher in smokers in general $(p=0.03)$ and was increased further in acute smokers over nonsmokers $(\mathrm{p}=0.02)$ and the chronic smoking group $(\mathrm{p}=0.04)$ (table 4). ENA-78 release was increased in smokers $(\mathrm{p}=0.02)$, but there was no significant difference between the chronic and acute smoking groups.

\section{Discussion}

The results of this study have shown that cigarette smoking is associated with an acute increase in neutrophils in BAL, concomitant with significantly higher IL-8 release from BAL leukocytes stimulated in vitro.

Table 2. - Bronchial lavage characteristics and cell differential

\begin{tabular}{|c|c|c|c|c|}
\hline & Chronic smoking & Acute smoking & Nonsmokers & p-value \\
\hline Return mL & $151.2 \pm 9.0$ & $157.9 \pm 11.8$ & $170.0 \pm 14.5$ & NS \\
\hline$\%$ Return & $63 \pm 4$ & $66 \pm 5$ & $70 \pm 6$ & \\
\hline Total cells $\times 10^{6}$ & $95.7 \pm 29.0$ & $54.8 \pm 9.0$ & $8.4 \pm 1.6$ & $<0.05 \mathrm{C} v s \mathrm{NS}$ \\
\hline$\%$ Viability & $84.4 \pm 2.8$ & $87.3 \pm 2.0$ & $83.0 \pm 2.5$ & NS \\
\hline \multicolumn{5}{|l|}{ Differential } \\
\hline Macrophages & $96.3 \pm 0.4$ & $94.4 \pm 0.9$ & $95.9 \pm 1.0$ & NS \\
\hline Absolute numbers $\times 10^{6}$ & $92.2 \pm 28.1$ & $52.0 \pm 9.0$ & $81.2 \pm 1.58$ & $<0.05 \mathrm{C} v s \mathrm{NS}$ \\
\hline \multirow[t]{2}{*}{ Lymphocytes } & $2.97 \pm 0.38$ & $3.21 \pm 0.58$ & $3.18 \pm 0.79$ & NS \\
\hline & $2.79 \pm 0.79$ & $1.56 \pm 0.26$ & $0.22 \pm 0.04$ & $<0.01 \mathrm{C} v s \mathrm{NS}$ \\
\hline \multirow[t]{2}{*}{ Neutrophils } & $0.59 \pm 0.25$ & $1.96 \pm 0.53$ & $0.79 \pm 0.29$ & $<0.05 \mathrm{C} v s \mathrm{~A}$ \\
\hline & $0.61 \pm 0.24$ & $0.99 \pm 0.32$ & $0.05 \pm 0.01$ & $<0.05 \mathrm{~A} v s \mathrm{NS}$ \\
\hline \multirow[t]{2}{*}{ Eosinophils } & $0.12 \pm 0.08$ & $0.46 \pm 0.18$ & $0.11 \pm 0.05$ & NS \\
\hline & $0.08 \pm 0.06$ & $0.25 \pm 0.11$ & $0.006 \pm 0.004$ & NS \\
\hline
\end{tabular}

Values are mean \pm SEM. C: chronic smoking; NS: nonsmokers; A: acute smoking. 
Table 3. - Interleukin-8 (IL-8), growth-related oncogene (GRO- $\alpha$ ) and extractable nuclear antigen (ENA)-78 in bronchoalveolar lavage fluid in nonsmokers and in healthy smokers overall, and in the chronic and acute smoking groups separately

\begin{tabular}{lcccc}
\hline & Nonsmokers & Smokers & $\begin{array}{c}\text { Chronic } \\
\text { smokers }\end{array}$ & $\begin{array}{c}\text { Acute } \\
\text { smokers }\end{array}$ \\
\hline $\mathrm{n}$ & 7 & 15 & 8 & 7 \\
$\mathrm{IL}-8 \mathrm{pg} \cdot \mathrm{mL}-1$ & $200 \pm 110$ & $120 \pm 30$ & $100 \pm 20$ & $140 \pm 70$ \\
$\mathrm{GRO}-\alpha \mathrm{pg} \cdot \mathrm{mL}^{-1}$ & $110 \pm 60$ & $70 \pm 10$ & $90 \pm 20$ & $50 \pm 8$ \\
ENA-78 $\mathrm{pg} \cdot \mathrm{mL}^{-1}$ & $1070 \pm 880$ & $5 \pm 5^{* *}$ & $0 \pm 0$ & $10 \pm 10$ \\
\hline
\end{tabular}

Values are mean \pm SEM. $* *: \mathrm{p}<0.01$ versus nonsmokers.

Cigarette smoke is the most important factor in the aetiology of chronic obstructive pulmonary disease (COPD). However, only one-third of smokers develop the centrilobular form of emphysema that is associated with cigarette smoking [13]. It is hypothesized that destruction of the alveolar structure in emphysema is mediated by increased proteolytic activity due to an imbalance between proteases, especially elastase, and $\alpha_{1}-\mathrm{Pi}$. Cigarette smoke has been implicated as the primary cause of the imbalance [14]. Smokers are known to have increased numbers of inflammatory cells in the interstitium and BALF. The total number of neutrophils found in BALF obtained from cigarette smokers is elevated [1]. In addition, long-term smoking increases the number of neutrophils in the peripheral circulation and in lung parenchyma $[15,16]$. Macrophages accumulate around the junction between the terminal bronchiole and acinus at the site of development of centrilobular emphysema [17].

Bronchoscopy and BAL were performed in smokers and nonsmokers. The smokers were asked to abstain for $12 \mathrm{~h}$ or to follow an acute smoking protocol. Compliance was confirmed by $\mathrm{COHb}$ measurements. There was a significant increase in the percentage and number of neutrophils in BALF in the acute smoking group. This study, in humans, thus controls for the smoking effect. It demonstrates that the influx of neutrophils into the airspaces of smokers occurs within $12 \mathrm{~h}$ of smoking. This is supported by studies in dogs and rats exposed acutely to cigarette smoke, which have demonstrated an influx of neutrophils, into the airways, recovered by BAL, beginning within 30$60 \mathrm{~min}$ after the cessation of smoking, peaking at 15-24 h and persisting for 1-2 weeks [14]. The increased number of neutrophils found in the BALF of cigarette smokers is, therefore, the result of the repeated acute insult of cigarette smoke inhalation. It has also been proposed that the increased epithelial permeability found in cigarette smokers is associated with the repeated acute injury caused by cigarette smoke [18] and that each inhalation of smoke may produce a short period of functional protease deficiency, which might lead to destruction of the lungs by frequent repetition over many years [2].

The above effect is not the result of changes in respiratory function measured by FEV1, BAL return, cell viability and differences in the smoking habits or duration of the two groups of smokers. Although small airways function was not measured, it is unlikely that the increased number of neutrophils found in the BALF of acute smokers was a sampling artefact resulting from acute small airways constriction, as acute cigarette smoking is known to cause sequestration and possibly activation of circulating neutrophils in the pulmonary vasculature in humans [2]. This effect may be important in the pathogenesis of emphysema since the pulmonary vascular bed acts as a large reservoir of neutrophils in intimate contact with the endothelium. Subsequent migration may be mediated through the release of chemotactic factors such as $\mathrm{C} 5 \mathrm{a}, \mathrm{LTB}_{4}$ and IL-8. Cigarette smoke can cause macrophages to release chemotactic factors for neutrophils [19].

The neutrophil is the predominant leukocyte associated with acute inflammation such as endotoxaemia. A significant neutrophilia is found in BAL in Pneumocystis carinii pneumonia (PCP) [20], ARDS, pulmonary fibrosis, both idiopathic and associated with collagen vascular disease, and hypersensitivity pneumonitis [21]. In PCP, IL-8 levels are elevated in BAL and correlate with relative BAL neutrophilia [20]. In at-risk patients BAL concentrations of IL-8 may have prognostic value for the development of ARDS [6]. Increased synthesis of IL-8 by mononuclear cells in rheumatoid arthritis [22] and idiopathic pulmonary fibrosis [23] has also been found.

In this study the concentrations were measured of IL-8, GRO- $\alpha$ and ENA-78 released into BALF and LCM in nonsmokers and healthy cigarette smokers and the chronic and acute effects of cigarette smoking were compared. There were no differences in IL-8 and GRO- $\alpha$ concentrations in BALF between nonsmokers and smokers, and ENA-78 levels were lower in the smokers. The pattern was the same

Table 4. - Interleukin-8 (IL-8), growth-related oncogenes (GRO- $\alpha$ ) and extractable nuclear antigen (ENA)-78 released into leukocyte-conditioned medium from mixed bronchoalveolar lavage leukocytes unstimulated or stimulated with lipopolysaccharide (LPS) in nonsmokers and in healthy smokers overall, and in the chronic and acute smoking groups separately

\begin{tabular}{|c|c|c|c|c|}
\hline & Nonsmokers & Smokers & Chronic smoking & Acute smoking \\
\hline Subjects n & 3 & 12 & 6 & 6 \\
\hline \multicolumn{5}{|l|}{ Unstimulated } \\
\hline IL-8 $\mathrm{pg} \cdot \mathrm{mL}^{-1}$ & $14,600 \pm 1600$ & $43,100 \pm 14,700$ & $25,600 \pm 5800$ & $60,600 \pm 28,100$ \\
\hline GRO- $\alpha$ pg $\cdot \mathrm{mL}^{-1}$ & $0 \pm 0$ & $120 \pm 30$ & $110 \pm 50$ & $130 \pm 50$ \\
\hline ENA-78 $\mathrm{pg} \cdot \mathrm{mL}^{-1}$ & $20 \pm 20$ & $390 \pm 200$ & $230 \pm 100$ & $550 \pm 390$ \\
\hline \multicolumn{5}{|l|}{ LPS $10 \mathrm{ng} \cdot \mathrm{mL}^{-1}$} \\
\hline IL-8 pg.mL-1 & $29,500 \pm 2800$ & $97,100 \pm 27,700$ & $59,900 \pm 28,800$ & $134,200 \pm 44,800 *$ \\
\hline GRO- $\alpha$ pg $\cdot \mathrm{mL}^{-1}$ & $10 \pm 10$ & $1720 \pm 910 * *$ & $2040 \pm 1770$ & $1410 \pm 670$ \\
\hline ENA-78 $\mathrm{pg} \cdot \mathrm{mL}^{-1}$ & $300 \pm 300$ & $690 \pm 260$ & $660 \pm 490$ & $710 \pm 250$ \\
\hline \multicolumn{5}{|l|}{ LPS $100 \mathrm{ng} \cdot \mathrm{mL}^{-1}$} \\
\hline IL-8 pg·mL-1 & $209,600 \pm 94,300$ & $103,400 \pm 21,400$ & $71,300 \pm 10,600$ & $135,400 \pm 38,600$ \\
\hline GRO- $\alpha \mathrm{pg} \cdot \mathrm{mL}^{-1}$ & $160 \pm 60$ & $3980 \pm 1370 *$ & $1170 \pm 400$ & $6790 \pm 2210^{+}$ \\
\hline ENA-78 $\mathrm{pg} \cdot \mathrm{mL}^{-1}$ & $0 \pm 0$ & $1260 \pm 320$ & $1080 \pm 470^{*}$ & $1440 \pm 460^{*}$ \\
\hline
\end{tabular}

Values are mean \pm SEM. *: $\mathrm{p}<0.05$ versus nonsmokers; + : $\mathrm{p}<0.05$ versus chronic smokers. 
in the chronic and acute smoking groups. In a previous study there was no significant difference in antigenic IL-8 concentrations between smokers $\left(26.7 \pm 6.2 \mathrm{pg} \cdot \mathrm{mL}^{-1}\right.$, mean \pm SEM) and nonsmokers $\left(14.6 \pm 2.4 \mathrm{pg} \cdot \mathrm{mL}^{-1}, \mathrm{p}=0.08\right)$ in BALF, although it was noted that the two smokers with the highest levels had the highest BALF neutrophil chemoattractant activity, the highest BAL cell count and the greatest content of IL- 8 messenger ribonucleic acid in their BAL macrophages [24]. The authors suggested that expression of this cytokine might be a marker for more intense airway inflammation and increased risk for COPD. Neutrophil chemoattractant activity in BALF from smokers and nonsmokers was, however, only partially blocked by anti-IL-8 antibody, supporting the presence of other neutrophil chemoattractants [24]. There have been no previous studies of GRO- $\alpha$ or ENA-78 in smokers.

Chemokine release from BAL leukocytes was studied, as BALF levels may not accurately reflect the microenvironment concentrations of chemokines important in neutrophil influx into the airspaces. There was no difference in IL-8, GRO- $\alpha$ or ENA-78 concentrations in LCM from unstimulated mixed leukocytes from smokers compared with nonsmokers. In general, chemokine release was increased by stimulation with LPS at 10 and $100 \mathrm{ng} \cdot \mathrm{mL}^{-1}$. Following LPS $\left(10 \mathrm{ng} \cdot \mathrm{mL}^{-1}\right)$ stimulation $\mathrm{GRO}-\alpha$ release was higher from smokers' leukocytes. IL-8 release was only higher from the acute smokers' leukocytes. At the higher level of LPS stimulation the release of both GRO- $\alpha$ and ENA-78, particularly GRO- $\alpha$ was higher from smokers' leukocytes following acute smoking.

The cause of the low levels of cytokines in BAL from smokers and the high levels released from BAL cells when stimulated ex vivo is unknown. It was speculated that this may be due to the presence of inhibitors of these cytokines in BAL, which were not present when the cells were stimulated in vitro.

The relative production of different chemokines may depend on the particular disease state [25]. The production of IL-8 and ENA-78 from pulmonary stromal and inflammatory cells is stimulus specific and, in general, is stimulated by LPS and the early response cytokines, IL-1 and tumour necrosis factor, which predominate in endotoxaemia $[3,26]$. IL-8 production has been shown to be regulated by oxidant stress in a number of different cell types, including mononuclear cells, A549 pulmonary type II epithelial cells, endothelial cells and skin fibroblasts [27-29] and this may involve the transcriptional nuclear factor (NF)$\kappa \mathrm{B}$, which is known to be sensitive to oxidants [28, 29]. Endotoxin potentiates this response and the present results suggest that the combination of oxidant stress from cigarette smoking, particularly acute oxidant stress, and endotoxin from Gram-negative bacteria or the presence of endotoxin in the workplace may potentiate the production of neutrophil chemotactic cytokines $[4,28]$. Further studies on these chemokines and the regulation of neutrophil influx into the airspaces of the lungs in cigarette smokers, in different pathological situations, will provide a greater understanding of smoking-related lung disease.

From the results of this study it can be concluded that there is an acute influx of neutrophils into the airspaces following cigarette smoking and that neutrophil chemokine release from mixed bronchoalveolar lavage leukocytes is influenced by cigarette smoking.
Acknowledgements: The authors wish to express their thanks to A. Langridge and S. Lannan for technical assistance and to the nursing staff in the Rayne Laboratory and Medical Out-Patient Department, City Hospital, Edinburgh.

\section{References}

1. Hunninghake GW, Crystal RG. Cigarette smoking and lung destruction. Am Rev Respir Dis 1983; 128: 833-838.

2. MacNee W, Wiggs B, Belzberg AS, Hogg JC. The effect of cigarette smoking on neutrophil kinetics in human lungs. N Engl J Med 1989; 321: 924-928.

3. Strieter RM, Lukacs NW, Standiford TJ, Kunkel SL. Cytokines and lung inflammation: mechanisms of neutrophil recruitment to the lung. Thorax 1993; 48: 765769.

4. Strieter RM, Kunkel SL. Acute lung injury: the role of cytokines in the elicitation of neutrophils. J Invest Med 1994; 42: 640-651.

5. Carre PC, Mortenson RL, King TE, Noble PW, Sable CL, Riches DWH. Increased expression of the interleukin-8 gene by alveolar macrophages in idiopathic pulmonary fibrosis. J Clin Invest 1991; 88: 1802-1810.

6. Donnelly SC, Strieter RM, Kunkel SL, et al. Interleukin-8 and development of adult respiratory distress syn- drome in at-risk patient groups. Lancet 1993; 341: 643-647.

7. Schroder J-M, Persoon NLM, Christophers E. Lipopolysaccharide-stimulated human monocytes secrete, apart from neutrophil-activating peptide 1 /interleukin-8, a second neutrophil-activating protein. $\mathrm{NH}_{2}$-terminal amino acid sequence identity with melanoma growth stimulatory activity. J Exp Med 1990; 171: 1091-1100.

8. Wen D, Rowland A, Derynck R. Expression and secretion of gro/MGSA by stimulated human endothelial cells. EMBO $J$ 1989; 8: 1761-1766.

9. Becker S, Quay J, Koren HS, Haskill S. Constitutive and stimulated MCP-1, GRO- $\alpha, \beta$ and $\gamma$ expression in human airway epithelium and bronchoalveolar macrophages. $A m$ J Physiol 1994; 266: L278-L286.

10. Golds EE, Mason P, Nyirkos P. Inflammatory cytokines induce synthesis and secretion of GRO protein and neutrophil chemotactic factor but not $\beta_{2}$-microglobulin in human synovial cells and fibroblasts. Biochem J 1989; 259: 585-588.

11. Schmouder RL, Strieter RM, Walz A, Kunkel SL. Epithelial-derived neutrophil-activating factor-78 production in human renal tubule epithelial cells and in renal allograft rejection. Transplantation 1995; 59: 118-124.

12. Donnelly SC, Strieter RM, Reid PT, et al. The association between mortality rates and decreased concentrations of interieukin-10 and interieukin-1 receptor antagonist in the lung fluids of patients with the adult respiratory distress syndrome. Ann Intern Med 1996; 125: 191-196.

13. Sherman CB. Health effects of cigarette smoking. Clin Chest Med 1991; 12: 643-658.

14. Janoff A, Pryor WA, Bengali ZH. Effects of tobacco smoke components on cellular and biochemical processes in the lung. Am Rev Respir Dis 1987; 136: 1058-1064.

15. Niewoehner D. Cigarette smoking, lung inflammation and the development of emphysema. J Lab Clin Med 1988; 111: $15-27$.

16. McGowan SE, Hunninghake GW. Neutrophils and emphysema. N Engl J Med 1989; 321: 968-970.

17. Niewoehner DE, Kleinerman J, Rice DB. Pathologic changes 
in the peripheral airways of young cigarette smokers. $N$ Engl J Med 1974; 291: 755-758.

18. Hogg JC. The effect of smoking on airway permeability. Chest 1983; 83: 1-2.

19. Hunninghake GW, Gadek JE, Fales HM, Crystal RG. Human alveolar macrophage-derived chemotactic factor for neutrophils. Stimuli and partial characterization. J Clin Invest 1980; 66: 473-483.

20. Benfield TL, van Steenwijk R, Nielsen TL, et al. Interleukin- 8 and eicosanoid production in the lung during moderate to severe Pneumocystis carinii pneumonia in AIDS: a role of interleukin- 8 in the pathogenesis of $P$. carinii pneumonia. Respir Med 1995; 89: 285-290.

21. Sibille Y, Reynolds HY. State of the art. Macrophages and polymorphonuclear neutrophils in lung defence and injury. Am Rev Respir Dis 1990; 141: 471-501.

22. Koch AE, Kunkel SL, Burrows JC, et al. Synovial tissue macrophages as a source of the chemotactic cytokine IL-8. J Immunol 1991; 147: 2187-2195.

23. Lynch JP, Standiford TJ, Rolfe MW, Kunkel SL, Strieter RM. Neutrophilic alveolitis in idiopathic pulmonary fibrosis. Am Rev Respir Dis 1992; 145: 1433-1439.
24. McCrea KA, Ensor JE, Nall K, Bleecker ER, Hasday JD. Altered cytokine regulation in the lungs of cigarette smokers. Am J Respir Crit Care Med 1994; 150: 695-703.

25. Villard J, Dayer-Pastore F, Hamacher J, Aubert JD, Schlegel-Haueter S, Nicod LP. GRO alpha and interleukin-8 in Pneumocystis carinii or bacterial pneumonia and adult respiratory distress syndrome. Am J Respir Crit Care Med 1995; 152: 1549-1554.

26. Lukacs NW, Kunkel SL, Alien R, et al. Stimulus and cell-specific expression of $\mathrm{C}-\mathrm{X}-\mathrm{C}$ and $\mathrm{C}-\mathrm{C}$ chemokines by pulmonary stromal cell populations. Am J Physiol 1995; 268: L856-L861.

27. DeForge LE, Preston AM, Takeuchi E, Kenney J, Boxer LA, Remick DG. Regulation of interleukin 8 gene expression by oxidant stress. J Biol Chem 1993; 268: 2556825576.

28. Metinko AP, Kunkel SL, Standiford TJ, Strieter RM. Anoxia-hyperoxia induces monocyte derived interleukin-8. J Clin Invest 1992; 90: 791-798.

29. Karakurum M, Shreeniwas R, Chen J, et al. Hypoxic induction of interleukin-8 gene expression in human endothelial cells. J Clin Invest 1994; 93: 1564-1570. 